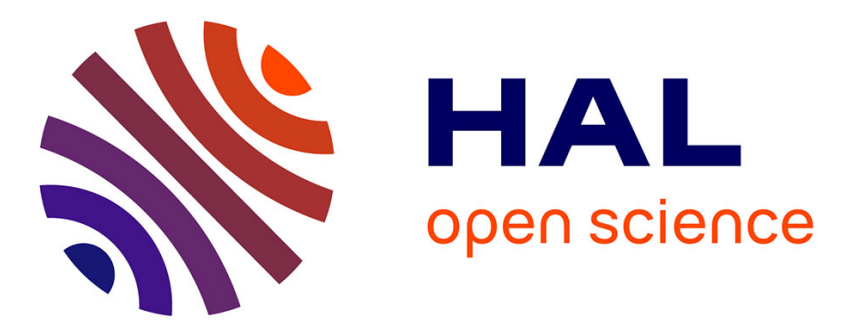

\title{
Clear-cell papillary renal cell carcinoma: 24 cases of a distinct low-grade renal tumor and a comparative genomic hybridization array study of 7 cases.
}

Julien Adam, Jerome Couturier, Vincent Moliné, Annick Vieillefond, Mathilde Sibony

\section{To cite this version:}

Julien Adam, Jerome Couturier, Vincent Moliné, Annick Vieillefond, Mathilde Sibony. Clear-cell papillary renal cell carcinoma: 24 cases of a distinct low-grade renal tumor and a comparative genomic hybridization array study of 7 cases.. Histopathology, 2011, 58 (7), pp.1064. 10.1111/j.13652559.2011.03857.x . hal-00655191

\section{HAL Id: hal-00655191 https://hal.science/hal-00655191}

Submitted on 27 Dec 2011

HAL is a multi-disciplinary open access archive for the deposit and dissemination of scientific research documents, whether they are published or not. The documents may come from teaching and research institutions in France or abroad, or from public or private research centers.
L'archive ouverte pluridisciplinaire HAL, est destinée au dépôt et à la diffusion de documents scientifiques de niveau recherche, publiés ou non, émanant des établissements d'enseignement et de recherche français ou étrangers, des laboratoires publics ou privés. 


\section{Histopathology}

\section{Clear-cell papillary renal cell carcinoma: 24 cases of a distinct low-grade renal tumor and a comparative genomic hybridization array study of 7 cases.}

\begin{tabular}{|c|c|}
\hline Journal: & Histopathology \\
\hline Manuscript ID: & HISTOP-10-10-0580.R1 \\
\hline Wiley - Manuscript type: & Original Article \\
\hline $\begin{array}{r}\text { Date Submitted by the } \\
\text { Author: }\end{array}$ & 02-Feb-2011 \\
\hline Complete List of Authors: & $\begin{array}{l}\text { Adam, Julien; AP-HP, Necker-Enfants Malades Hospital, Pathology; } \\
\text { Université Paris Descartes } \\
\text { Couturier, Jerome; Institut Curie, Service de Pathologie } \\
\text { Moliné, Vincent; Hôpital Saint-Joseph, Pathology } \\
\text { Vieillefond, Annick; AP-HP, Hôpital Cochin, Pathology } \\
\text { Sibony, Mathilde; AP-HP, Hôpital Tenon, Pathology }\end{array}$ \\
\hline Keywords: & Renal tumor, Clear-cell papillary renal cell carcinoma, Array-CGH \\
\hline
\end{tabular}

\section{SCHOLARONE" Manuscripts}




\section{Clear-cell papillary renal cell carcinoma: 24 cases of a distinct low-grade} renal tumor and a comparative genomic hybridization array study of 7 cases.

Julien Adam, ${ }^{1,2}$ Jérôme Couturier, ${ }^{3}$ Vincent Molinié, ${ }^{4}$ Annick Vieillefond, ${ }^{2,5}$ Mathilde Sibony ${ }^{6,7}$

\section{Affiliations:}

${ }^{1}$ Department of Pathology, Hôpital Necker-Enfants Malades, AP-HP, Paris; ${ }^{2}$ Université Paris Descartes, Paris; ${ }^{3}$ Department of Genetics, Institut Curie, Paris; ${ }^{4}$ Department of Pathology, Hôpital Saint-Joseph, Paris; ${ }^{5}$ Department of Pathology, Hôpital Cochin, AP-HP, Paris; ${ }^{6}$ Université Pierre et Marie Curie, Paris; ${ }^{7}$ Department of Pathology, Hôpital Tenon, AP-HP, Paris, France.

\section{Address for correspondence:}

Dr. Julien Adam, Service d'Anatomie et Cytologie Pathologiques, Hôpital Necker-Enfants Malades, 149 rue de Sèvres, 75743 Paris Cedex 15, France. Fax: 00331444949 99. E-mail: julien.adam@nck.aphp.fr

Abstract word count: 180 .

Word count: 2550.

Tables: 4 .

Figures: 1.

Key words:

Renal tumor, clear-cell papillary renal cell carcinoma, array-CGH. 


\begin{abstract}
:
Aim: To report clinicopathological and genomic characteristics of clear-cell papillary renal carcinoma (ccpRCC), a rare, recently characterized renal tumor entity.

Methods and results: Twenty-four renal tumors identified as ccpRCC were gathered. Data from comparative genomic hybridization on microarrays (array-CGH) were obtained for 7 of them. Most tumors (58\%) occurred in the absence of renal disease. Mean patient age was 58.1 years. Tumors were small (mean size: $2.4 \mathrm{~cm}$ ) and classified as pT1a. Histological characteristics consisted of tubes and papillae lined by a single layer of small clear cells harboring low-grade nuclei (Fuhrman grade 1 or 2). Architectural variations, with compact areas ( $41 \%$ of cases) and a micro- or macrocystic pattern (67\% of cases) were frequently observed. Immunostaining demonstrated diffuse, strong expression of cytokeratin 7 and vimentin, whereas CD10, racemase, RCC antigen, TFE3 and TFEB were consistently negative. In 7 tumors, array-CGH detected no chromosome imbalances.

Conclusion: ccpRCC were differentiated from other renal neoplasms by the specific association of histopathological and immunohistochemical features, without characteristic genomic imbalances. Clinical, histopathological and genomic data suggested that this tumor have low potential for malignancy.
\end{abstract}




\section{Introduction}

Classification of renal epithelial neoplasms uses morphological, immunohistochemical and genetic features ${ }^{1}$. Accurate classification of renal tumors is critical for prognostic and therapeutic purposes, since new targeted therapy eligibility may rely on tumor subtype ${ }^{2}$. New subtypes of renal tumors have been described on the basis of their histological, immunophenotypic and genomic characteristics ${ }^{3}$, distinguishing them from the main subtypes of renal cell tumors (clear-cell renal cell carcinoma [ccRCC], papillary renal cell carcinoma [pRCC], chromophobe carcinoma and oncocytoma). In particular, some tumors display characteristics intermediate between clear-cell and papillary carcinomas ${ }^{4-7}$. In this group, carcinoma associated with the Xp11 translocation was individualized on the basis of a specific cytogenetic translocation, correlated with a specific clinical and histopathological profile $\mathrm{e}^{8-9}$. In the remaining cases, fluorescent in situ hybridization (FISH) ${ }^{6,7}$ study or single nucleotide polymorphism (SNP) array ${ }^{10}$ might help to classify renal tumors.

Recent studies have described clear-cell papillary renal cell carcinoma (ccpRCC) as a new type of renal neoplasm ${ }^{11-13}$. Clinically, it was initially observed in end-stage kidney disease ${ }^{11}$, but some cases have been reported in otherwise normal kidneys ${ }^{12-13}$. It presents as small renal tumors of low stage and low Fuhrman grade, and has a particular histological pattern consisting of small clear cells with tubular and papillary architecture and a specific imunohistochemical profile with constant expression of cytokeratin 7, whereas CD10, racemase and TFE3 are negative. Previously, this tumor might have been classified as clearcell carcinoma with papillary architecture based on cytological features, or as papillary carcinoma based on architectural and immunohistochemical characteristics. No loss of chromosome $3 p$ and no gain of chromosomes 7 and 17 were identified by $\mathrm{FISH}^{13}$. Together, those data suggested that this tumor might be a specific entity in the spectrum of renal neoplasms ${ }^{12,13}$. However, they were based on very few studies, and no genome-wide studies of these tumors have been reported to our knowledge.

The current study aims to identify clinical, histopathological and immunophenotypic features in a series of 24 ccpRCC arising in 23 patients. In addition, 7 of these tumors could be analyzed by comparative genomic hybridization (CGH) array. Our data confirm the clinical, morphological and genomic homogeneity of this subset of renal tumors and support the 
hypothesis of the specific nature of this renal neoplasm, which differs from ccRCC and pRCC.

\section{Materials and methods}

\section{Pathology specimens}

Twenty-one cases of ccpRCC were identified from cases diagnosed or addressed for consultation to the authors. All cases were reviewed by three pathologists (JA, MS and AV). Clinical data were recorded at the time of diagnosis. Tissue was obtained from nephrectomy (14 cases), tumorectomy ( 7 cases) or biopsy ( 1 case); specimens were fixed in formalin or formalin-acetic acid. Slides were examined after staining by hematein-eosin-safran. One paraffin-embedded block of each tumor was selected for immunohistochemical evaluation. Frozen tissue samples were available for CGH on microarray for 7 tumors.

\section{Immunohistochemical study}

Briefly, sections were cut at $4 \mu \mathrm{m}$ from paraffin-embedded blocks, deparaffinized and rehydrated. Immunohistochemical staining was performed using the avidin-biotin-peroxidase method. Antibody references and dilutions are shown in table 1. All stainings were performed in a Dako Autostainer (Trappes, France) or a NexES Ventana (Illkirch, France) automated stainer. Immunolabellings were considered positive when diffuse strong staining was observed in more than 90 percent of tumor cells. Staining was considered negative if less than $5 \%$ of tumor cells were labeled. Staining of renal parenchyma adjacent to each tumor was used as internal positive control for all antibodies.

\section{CGH array}

Seven cases for which frozen tumor material was available were analyzed by array-CGH. All specimens were checked for showing more than $60 \%$ tumor cells on a frozen section prior to DNA extraction. Five samples were analyzed on a genome-wide 5K DNA microarray made of BAC and PAC clones, with $1 \mathrm{Mb}$ average resolution (CIT / INSERM U830), Hybridization of tumor and reference DNA and visualization of genomic profiles were carried out as previously described ${ }^{14}$. Two samples were analyzed on a NimbleGen $72 \mathrm{~K}$ oligonucleotide 
microarray (Roche NimbleGen, Madison WI, USA), following the procedure recommended by the supplier.

\section{Results}

\section{Clinical findings}

Clinical characteristics of our patients with ccpRCC are summarized in table 2. The male:female gender ratio was 2.3:1. Mean age at diagnosis was 58.1 years (range: 39 to 78). Fourteen patients (58\%) did not present any history of renal disease, nor impairment of renal function. In those cases, histological examination of renal parenchyma distant from the tumor found no evidence of associated renal disease, apart from vascular lesions and focal interstitial fibrosis possibly related to patient age. One patient had a history of a renal homolateral tumor and one presented with multiple cysts of unknown origin in both kidneys. Seven patients (29\%) presented with end-stage kidney disease. One of them was a renal transplant recipient and developed a tumor on a native kidney. One patient (case no. 21) with end-stage kidney disease developed two metachronous ccpRCC (one on each kidney; time interval: one year). Two patients presented with multiple unilateral (case no. 11) or bilateral (case no. 24) small renal tumors identified as ccpRCC; in each case, the largest tumor was analyzed. Other patients presented single tumors. One patient (case no. 17;4\%) developed a tumor on an atrophic ectopic kidney. Clinically and radiologically, all patients were NOM0.

\section{Pathological features}

Macroscopically, the average size of tumors was $24 \mathrm{~mm}$ (range: 18 to $60 \mathrm{~mm}$ ). They presented as a solid nodule slightly clearer than the adjacent renal cortical parenchyma, with no or very limited hemorrhagic areas and no necrotic areas. All tumors were clearly delineated and encapsulated. The capsule or fibrous pseudocapsule was usually thin and regular. Tumors exhibited a non-prominent macrocystic component. One tumor was mainly cystic with a small solid nodule. Adjacent parenchyma appeared either normal or abnormal depending on whether associated renal disease was present.

Microscopically (table 3), all tumors showed prominent tubulo-papillary architecture, composed of various-sized tubes lined by a cubic epithelium. Tubes often presented abundant branching. Papillary projections presented either a thin or thick fibrovascular core. Cells were small to medium-sized, and presented optically clear cytoplasms similar to those of clear-cell 
carcinoma tumor cells. Nuclei were small, round, with regular borders and chromatin patterns, corresponding to "low-grade" nuclei (Fuhrman grade 1 or 2). Polarization of nuclei away from the basal pole of the cells was characteristic: nuclei were aligned in the apical pole or in the middle of cells, conferring an appearance similar to that of endometrial glands in early secretory phase. Although not observed in all areas of the tumor, this particular aspect was present in all cases. No area of necrosis was observed. Representative histopathological aspects of ccpRCC are illustrated in Figure 1A-D.

In addition to these typical features, variations in the architectural pattern and cellular aspects were observed in most tumors. Architectural variations included compact areas and macro- or microcystic formations. Compact areas consisted of compacted tubules (easily observed after cytokeratin 7 immunostaining) in a scant vascular stroma, resulting in a solid appearance. Dilated and ramified tubules lined by cylindrical clear cells were consistently scattered throughout these areas. Vasculature was abundant but showed no characteristics of clear-cell carcinoma. Cysts were frequently observed (67\% of cases). They were lined by small clear cells having a similar morphological aspect and immunohistochemical profile as typical areas of the tumor. In two tumors, cystic architecture was prominent ( $>50 \%$ of tumor area). On computed tomography evaluation, one of these cases was classified as category III according to the Bosniak classification. Cell variants were focal and included large cells with a clear cytoplasm and cells with a slightly eosinophilic cytoplasm. Stroma was fibrous and frequently edematous or, more rarely, focally hemorragic. All tumors were microscopically well delineated by a fibrous capsule or pseudocapsule of variable thickness. Pathological tumor stage according to WHO 2004 classification was pT1 in all cases (pT1a or pT1b depending on the size of the tumor).

\section{Immunohistological features}

Results of immunohistochemical staining are summarized in table 4 and illustrated in Figure 1E-F. All tumors presented remarkable uniformity in their immunohistological pattern. Tumor cells diffusely and strongly expressed cytokeratin 7 and vimentin in all 12 cases tested. Expression of EMA was noted in 12/12 cases. Absence of CD10 and racemase expression was observed in all cases. There was no expression of RCC in 12 cases tested. Immunostaining for TFE3 and TFEB was negative in all cases. 
Array-CGH analysis

All 7 cases analyzed showed a flat genomic profile, with no detectable chromosome imbalance (Figure 1G).

\section{Discussion}

Most adult renal neoplasms have been characterized and classified on the basis of their histological, immunohistochemical and cytogenetic profiles ${ }^{1,3}$. For example, in ccRCC, loss of chromosome $3 \mathrm{p}$ leading to inactivation of the VHL gene is consistently observed, accompanied by alterations in other genes ${ }^{15,16}$; in pRCC, trisomy 7 and 17 and other nonrandom chromosomal gains are seen ${ }^{17,18}$. Recently, several rare epithelial neoplasms have been individualized, as their phenotypic and cytogenetic characteristics were homogenous but different from ccRCC and pRCC. Among these tumors, icluding TFE translocation-associated translocation carcinoma ${ }^{8}$ and tubulo-mucinous ${ }^{20}$ renal cell carcinoma, neither loss of $3 p$ nor a gain in chromosomes 7 and 17 was observed. On the basis of cytogenetic data, these tumors were considered specific entities rather than variants of ccRCC or pRCC. Thus far, in most of these "new entities", no specific cytogenetic abnormalities were seen. Thus, in daily practice, histological and immunohistochemical features remain the most pertinent elements for diagnosis of renal epithelial neoplasms. However, despite significant improvement in classification of renal epithelial neoplasms, overlapping histologic features between certain renal neoplasms remain, making subclassification difficult.

Renal tumors presenting with papillary architecture and clear cells are often difficult to classify. Some ccRCC have been shown to present papillary architecture, while others may present cells with clarified rather than clear cytoplasms. Some studies demonstrated that search for characteristic loss of $3 p$ or chromosome 7 and 17 trisomies using FISH or SNParray could enable accurately classifying many of these tumors as pRCC and ccRCC $^{4-7,10}$. Among remaining tumors, a new group, called ccpRCC, has recently been described.

In 2006, Tickoo et al. ${ }^{11}$ described ccpRCC as a new renal neoplasm in patients with end-stage kidney disease. This tumor can also be observed in patients with no renal disease. In a recent study, Aydin et al. ${ }^{13}$ observed that ccpRCC are small low-stage (pT1) tumors, having varying 
but characteristic morphologic features and a characteristic immunoprofile. FISH demonstrated that ccpRCC does not harbor loss of $3 \mathrm{p}$, nor a gain in chromosomes 7 or $17,,^{12,13}$ suggesting that this group of tumors should not be considered a morphological variant of ccRCC or pRCC.

In our study, we collected 24 tumors from 22 patients and diagnosed them as ccpRCC; we analyzed their morphologic and immunohistochemical features and, for 7 of them, genomic profiles by array-CGH. This series demonstrates that ccp-RCC may occur in otherwise normal kidney. We confirm that variable but specific histological features characterize this tumor. The typical morphological aspect consists of clear cells arranged in a tubular papillary pattern lacking sinusoidal small vessels typical of ccRCC and foamy macrophages seen in type 1 pRCC. Our series shows that small or large cyst formation is a frequent feature of this tumor and that the cystic component may sometimes be prominent. Ccp-RCC shows immunoreactivity to antibodies against CK7 and vimentin and lacks staining for CD10, AMACR (racemase) and RCC antigen. These findings are consistent with previously reported $\operatorname{data}^{12,13}$.

Our observations led us to consider that morphologic and immunohistochemical features of ccpRCC distinguish this tumor from other RCC with clear-cell cytomorphology and/or papillary architecture. This differential diagnosis is of particular importance for the prognosis linked to these entities and their eligibility for new targeted therapies, especially in ccRCC. This is particularly challenging, since clear-cell carcinomas may exhibit papillary or pseudopapillary areas, and pRCCs may contain cells with clarified cytoplasm. In contrast to clear-cell carcinoma, ccpRCC demonstrates a tubulo-papillary architecture. Tumor cells strongly express cytokeratin 7 but do not express CD10, racemase (AMACR) or RCC antigen, even in "large-cell" areas, the morphological aspect of which may be quite similar to ccRCC. Contrary to papillary carcinomas, ccpRCC is composed of cells with clear (optically "empty") cytoplasm. In addition, tumor cells express vimentin but not racemase, a commonly expressed antigen in papillary carcinomas. The third differential diagnosis is TFE translocation-associated RCC. Although this tumor may present with clear-cell cytomorphology and papillary architecture, it occurs most often in young adults, is of high grade and demonstrates an immunohistochemical profile markedly different from that of ccpRCC, with expression of CD10, AMACR and TFE3 or TFEB. Thus, along with histological appearance, the immunohistochemical profile is particularly important for 
distinguishing between ccpRCC, ccRCC and pRCC. Whether ccpRCC can be observed in association with ccRCC or pRCC remains to be determined. None of the tumors we observed demonstrated such a feature. However, we observed that some ccpRCC may present small foci with papillary architecture and an immunoprofile similar to ccpRCC (unpublished observations). Thus, we suggest that a ccpRCC diagnosis should be proposed only in the absence of areas that can be characterized, morphologically and immunohistochemically as ccRCC or pRCC.

Another challenging issue lies in the possibility of diagnosing ccpRCC on needle biopsy specimen. This technique has been shown to be accurate for diagnosis of renal tumors ${ }^{19}$. In one of our patients, it was possible because of the characteristic morphological aspect and immunohistochemical data. However, it can be difficult when confronted with compact or "large-cell" areas, since the morphological appearance is close to that of ccRCC. However, immunohistochemical studies are able to demonstrate cytokeratin 7 expression and lack of immunoreactivity for CD10 and racemase (AMACR) in these areas. Use of FISH has been recently reported and could constitute another useful tool ${ }^{20}$.

To our knowledge, our study is the first array-CGH study on ccpRCC. The 7 patients presented a flat profile, demonstrating no genomic imbalance. This particular genomic profile is different from data reported in renal cell neoplasms, in particular ccRCC and pRCC. Indeed, these tumors nearly always present genomic imbalances, with $3 p$ loss observed in ccRCC, and gains in chromosomes 7 and 17 observed in pRCC. Though array-CGH cannot detect balanced chromosomal rearrangements, we cannot exclude the possibility that ccpRCC harbors balanced cytogenetic abnormalities.

Taken together, histological observations, the immunophenotypic profile and genomic data suggest that ccpRCC is a specific renal neoplasm distinct from ccRCC and pRCC. Moreover, pT1 stage at diagnosis, the absence of vascular or perirenal extension, a histological aspect consistent with a "low-grade tumor" and the absence of genomic imbalance lead us to believe that ccpRCC have very limited (if any) potential for malignancy. In our study, we were unable to document follow-up of patients. The study by Aydin et al. ${ }^{13}$ reported that all 20 patients were disease-free at follow-up (mean: 27.4 months). The prognosis of this tumor remains to be characterized, in particular to determine whether some patients had metastatic disease at diagnosis or during follow up. 
In summary, our series demonstrates that ccpRCC can be considered a specific type of renal tumor, occurring both in end-stage kidney disease and in patients with no renal disease, and characterized on the basis of histological, immunohistochemical and genomic features. Our findings highlight diagnostic criteria for ccpRCC, relying mainly on histological and immunohistochemical features. The current study also provides strong arguments for considering that this neoplasm have a low (or possibly non-existent) potential for malignancy. Thus, for clarity purposes, we propose naming this tumor "low-grade clear-cell papillary renal carcinoma" or "clear-cell papillary renal tumor". 


\section{Acknowledgments}

The authors acknowledge the pathologists who provided cases for this study: Dr P. Camparo,

Dr E. Compérat, Dr MD. Martin-Martinez, Dr C. Mazerolles, Dr. P. Michenet, Dr. R. Plès,

Dr. P. Rouvier and Dr V. Verkarre. 


\section{References}

1. Eble JN, Sauter G, Epstein JI, Sesterhenn IA (Editors). World Health Organization Classification of Tumours. Pathology and Genetics of Tumours of the Urinary System and Male Genital Organs. IARC Press;Lyon;2004.

2. Ficarra V, Brunelli M, Cheng L, et al. Prognostic and Therapeutic Impact of the Histopathologic Definition of Parenchymal Epithelial Renal Tumors. Eur. Urol. 2010. Epub ahead of print.

3. Srigley JR, Delahunt B. Uncommon and recently described renal carcinomas. Mod. Pathol. 2009;22 Suppl 2 ;S2-S23.

4. Füzesi L, Gunawan B, Bergmann F, Tack S, Braun S, Jakse G. Papillary renal cell carcinoma with clear cell cytomorphology and chromosomal loss of $3 p$. Histopathology 1999;35;157-61.

5. Salama ME, Worsham MJ, DePeralta-Venturina M. Malignant papillary renal tumors with extensive clear cell change: a molecular analysis by microsatellite analysis and fluorescence in situ hybridization. Arch. Pathol. Lab. Med. 2003;127;1176-81.

6. Mai KT, Faraji H, Desantis D, Robertson SJ, Belanger EC, Levac J. Renal cell carcinoma with mixed features of papillary and clear cell cytomorphology: a fluorescent in situ hybridization study. Virchows Arch. 2010;456 ;77-84.

7. Gobbo S, Eble JN, Maclennan GT, et al. Renal cell carcinomas with papillary architecture and clear cell components: the utility of immunohistochemical and cytogenetical analyses in differential diagnosis. Am. J. Surg. Pathol. 2008;32;1780-6.

8. Argani $\mathrm{P}$, Antonescu CR, Couturier J, et al. PRCC-TFE3 renal carcinomas: morphologic, immunohistochemical, ultrastructural, and molecular analysis of an entity associated with the $t(X ; 1)(p 11.2 ; q 21)$. Am. J. Surg. Pathol. 2002;26;1553-66.

9. Camparo $\mathrm{P}$, Vasiliu V, Molinie V, et al. Renal translocation carcinomas: clinicopathologic, immunohistochemical, and gene expression profiling analysis of 31 cases with a review of the literature. Am. J. Surg. Pathol. 2008;32;656-70.

10. Kim HJ, Shen SS, Ayala AG, et al. Virtual-karyotyping with SNP microarrays in morphologically challenging renal cell neoplasms: a practical and useful diagnostic modality. Am. J. Surg. Pathol. 2009;33 ;1276-86.

11. Tickoo SK, dePeralta-Venturina MN, Harik LR, et al. Spectrum of epithelial neoplasms in end-stage renal disease: an experience from 66 tumor-bearing kidneys 
with emphasis on histologic patterns distinct from those in sporadic adult renal neoplasia. Am. J. Surg. Pathol. 2006;30;141-53.

12. Gobbo S, Eble JN, Grignon DJ, et al. Clear cell papillary renal cell carcinoma: a distinct histopathologic and molecular genetic entity. Am. J. Surg. Pathol. 2008;32;1239-45.

13. Aydin H, Chen L, Cheng L, et al. Clear Cell Tubulopapillary Renal Cell Carcinoma: A Study of 36 Distinctive Low-grade Epithelial Tumors of the Kidney. Am. J. Surg. Pathol. 2010. Epub ahead of print.

14. Trolet J, Hupé P, Huon I, et al. Genomic profiling and identification of high-risk uveal melanoma by array $\mathrm{CGH}$ analysis of primary tumors and liver metastases. Invest. Ophthalmol. Vis. Sci. 2009;50;2572-80.

15. Gnarra JR, Tory K, Weng Y, et al. Mutations of the VHL tumour suppressor gene in renal carcinoma. Nat. Genet. 1994;7:85-90.

16. Shuin T, Kondo K, Torigoe S, et al. Frequent somatic mutations and loss of heterozygosity of the von Hippel-Lindau tumor suppressor gene in primary human renal cell carcinomas. Cancer Res. 1994;54:2852-5.

17. Jiang F, Richter J, Schraml P, et al. Chromosomal imbalances in papillary renal cell carcinoma: genetic differences between histological subtypes. Am J Pathol. 1998 Nov;153(5):1467-73.

18. Brunelli M, Eble JN, Zhang S, Martignoni G, Cheng L. Gains of chromosomes 7, 17, 12, 16, and 20 and loss of Y occur early in the evolution of papillary renal cell neoplasia: a fluorescent in situ hybridization study. Mod. Pathol. 2003;16;1053-9.

19. Kümmerlin IP, Smedts F, ten Kate FJ, et al. Cytological punctures in the diagnosis of renal tumours: a study on accuracy and reproducibility. Eur. Urol. 2009;55;187-95.

20. Roh MH, Dal Cin P, Silverman SG, Cibas ES. The application of cytogenetics and fluorescence in situ hybridization to fine-needle aspiration in the diagnosis and subclassification of renal neoplasms. Cancer Cytopathol. 2010;118;137-45. 


\section{Figure legend}

Figure 1. Histological, immunohistochemical and genomic features of ccpRCC. A. Typical histological aspect of ccpRCC: tubulo-papillary architecture with abundant branching, tubules lined by a single layer of small cuboid clear cells with pseudoendometrioid aspect. B. Compact areas: compacted tubules, scant stroma, dilated and ramified tubules lined by cylindric clear cells. C. Large cell areas (right of the figure). D. Edematous stroma. E. Cytokeratin 7 immunoreactivity in typical areas. F. Cytokeratin 7 immunoreactivity in large cell areas (above the figure). G. Representative array-CGH analysis of ccpRCC: no chromosomal imbalance could be detected. 
Table 1: Summary of antibodies used.

\begin{tabular}{llll}
\hline Antibody & Clone & Dilution & Producer \\
\hline Cytokeratin 7 & OV-TL 12/30 & $1: 50$ & Dako \\
Vimentin & V9 & $1: 200$ & Dako \\
CD10 & 56 C6 & $1: 50$ & Novocastra \\
Racemase (AMACR) & $13 \mathrm{H} 4$ & $1: 200$ & Dako \\
TFE3 & Polyclonal (P-16) & $1: 400$ & Santa Cruz \\
TFEB & H-125 & $1: 200$ & Santa Cruz \\
Anti-RCC marker antibody & - & $1: 100$ & Dako \\
EMA & E29 & $1: 100$ & Dako \\
\hline
\end{tabular}

AMACR, alpha-methylacyl-CoA racemase ; EMA, epithelial membrane antigen. 
Table 2: Patient characteristics.

\begin{tabular}{|c|c|c|c|c|c|c|c|c|}
\hline $\begin{array}{c}\text { Case } \\
\text { number }\end{array}$ & Sex & Age & $\begin{array}{l}\text { Number of } \\
\text { tumors }\end{array}$ & $\begin{array}{c}\text { Renal } \\
\text { function }\end{array}$ & $\begin{array}{c}\text { Associated } \\
\text { renal } \\
\text { disease }\end{array}$ & $\begin{array}{c}\text { Intervention } \\
\text { type }\end{array}$ & $\begin{array}{c}\text { Tumor } \\
\text { size } \\
(\mathrm{mm}) \\
\end{array}$ & $\begin{array}{c}\text { TNM stage } \\
\text { (WHO 2009 } \\
\text { classification) }\end{array}$ \\
\hline $1^{*}$ & M & 64 & 1 & Normal & None & $\mathrm{RN}$ & 60 & T1N0M0 \\
\hline 2 & $\mathrm{~F}$ & 39 & 1 & Normal & None & $\mathrm{T}$ & 23 & T1N0M0 \\
\hline $3 *$ & M & 52 & 1 & Normal & None & $\mathrm{RN}$ & 25 & T1N0M0 \\
\hline 4 & M & 55 & 1 & Normal & None & $\mathrm{T}$ & 25 & T1N0M0 \\
\hline 5 & $\mathrm{~F}$ & 78 & 1 & Normal & None & $\mathrm{T}$ & 23 & T1N0M0 \\
\hline $6^{*}$ & $\mathrm{~F}$ & 45 & 1 & Normal & None & $\mathrm{RN}$ & 25 & T1N0M0 \\
\hline 7 & $\mathrm{~F}$ & 45 & 1 & Normal & None & $\mathrm{T}$ & 35 & T1N0M0 \\
\hline 8 & M & 73 & 1 & Normal & None & $\mathrm{T}$ & 28 & T1N0M0 \\
\hline $9 *$ & $\mathrm{~F}$ & 69 & 1 & Normal & None & $\mathrm{RN}$ & 25 & T1N0M0 \\
\hline 10 & M & 62 & 1 & Normal & None & $\mathrm{RN}$ & Unknown & T1N0M0 \\
\hline 11 & $\mathrm{~F}$ & 60 & $\begin{array}{c}8 \\
\text { (unilateral } \\
\text { tumors) }\end{array}$ & Normal & None & $\mathrm{RN}$ & 2 to 30 & T1N0M0 \\
\hline 12 & M & 42 & 1 & Normal & None & Unknown & Unknown & T1N0M0 \\
\hline 13 & M & 69 & 1 & Normal & None & $\mathrm{T}$ & 10 & T1N0M0 \\
\hline 14 & M & 48 & 1 & Normal & $\begin{array}{l}\text { Lithiasis } \\
\text { homolateral } \\
\text { to tumor }\end{array}$ & $\mathrm{T}$ & 24 & T1N0M0 \\
\hline 15 & M & 60 & 1 & Normal & $\begin{array}{l}\text { Multiples } \\
\text { cysts }\end{array}$ & $\mathrm{RN}$ & Unknown & T1N0M0 \\
\hline $16^{*}$ & M & 77 & 1 & Impaired & Unknown & RN & 25 & T1N0M0 \\
\hline 17 & M & 63 & 1 & Impaired & $\begin{array}{l}\text { Ectopic } \\
\text { kidney }\end{array}$ & RN & 18 & T1N0M0 \\
\hline $18^{*}$ & M & 62 & 1 & Impaired & ESRD & $\mathrm{RN}$ & 15 & T1N0M0 \\
\hline 19 & Unknown & 53 & 1 & Impaired & ESRD & Unknown & Unknown & T1N0M0 \\
\hline 20 & M & 62 & 1 & Impaired & ESRD & $\mathrm{RN}$ & 13 & T1N0M0 \\
\hline 21 & M & 53 & $\begin{array}{c}2 \text { (bilateral } \\
\text { tumors) }\end{array}$ & Impaired & ESRD & RN & 15 et 25 & T1N0M0 \\
\hline 22 & M & Unknown & 1 & Impaired & ESRD & $\mathrm{RN}$ & 15 & T1N0M0 \\
\hline $23 *$ & M & 68 & 1 & Impaired & ESRD & Unknown & Unknown & T1N0M0 \\
\hline 24 & $\mathrm{~F}$ & 42 & $\begin{array}{c}\text { Multiple, } \\
\text { bilateral } \\
\text { tumors }\end{array}$ & Impaired & ESRD & RN & $<1$ to 25 & T1N0M0 \\
\hline
\end{tabular}

* Cases studied by array-CGH

ESRD, end-stage renal disease; F, female; M, male; RN, radical nephrectomy; $\mathrm{T}$, tumorectomy. 
Table 3: Histological features of clear cell papillary renal cell carcinoma.

\begin{tabular}{ll}
\hline Histological features & Number of cases \\
\hline Architectural features & $24 / 24(100 \%)$ \\
Tubulopapillary architecture & $16 / 24(67 \%)$ \\
Macro- or microcystic areas & $10 / 24(42 \%)$ \\
Compact areas & $2 / 24(8 \%)$ \\
Prominent cystic architecture (>50\% of tumor area) & \\
& \\
Cellular features & $24 / 24(100 \%)$ \\
Cuboidal small cells with low-grade central nuclei & $24 / 24(100 \%)$ \\
Polarization of nuclei away from basal pole (pseudoendometrial & \\
appearance) & $9 / 24(38 \%)$ \\
Foci of large cells & $2 / 24(8 \%)$ \\
Foci of cells with slightly eosinophilic cytoplasm & \\
& \\
Stroma & \\
Fibrous stroma delineating nodules & $24 / 24(100 \%)$ \\
Edema & $8 / 24(33 \%)$ \\
Hemorrhagic areas & $1 / 24(4 \%)$ \\
Heterotopic bone & $1 / 24(4 \%)$ \\
Necrosis & $0 / 24(0 \%)$ \\
Aggregates of foamy macrophages & $0 / 24(0 \%)$ \\
Psammomatous calcification & $0 / 24(0 \%)$ \\
& \\
\hline & \\
& \\
& \\
&
\end{tabular}


Table 4: Immunohistological features of ccpRCC.

\begin{tabular}{ll}
\hline Antigen & Immunohistochemical staining \\
\hline Cytokeratin 7 & Diffuse and intense staining in 24/24 cases \\
Vimentin & Diffuse staining in 12/12 cases \\
CD10 & No staining in 24/24 cases \\
Racemase (AMACR) & No staining in 24/24 cases \\
TFE3 and TFEB & No staining in 12/12 cases \\
RCC antigen & No staining in 12/12 cases \\
EMA & Diffuse staining in $12 / 12$ cases \\
\hline
\end{tabular}



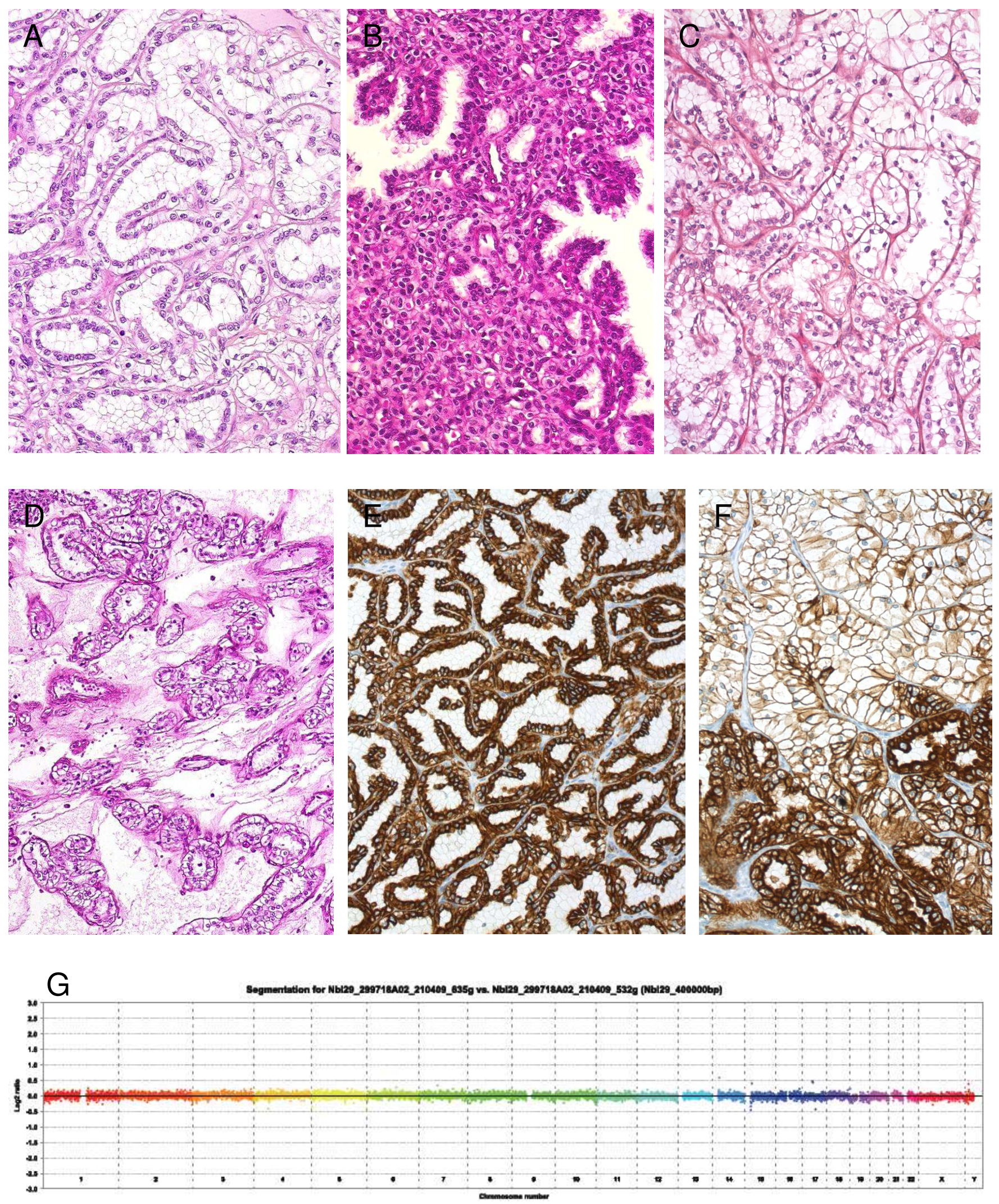